\title{
Increasing Water Intake of Children and Parents in the Family Setting: A Randomized, Controlled Intervention Using Installation Theory
}

\author{
Saadi Lahlou ${ }^{a}$ Sabine Boesen-Mariani ${ }^{b} \quad$ Bradley Franks $^{a} \quad$ Isabelle Guelinckx ${ }^{b}$ \\ aDepartment of Social Psychology, London School of Economics and Political Science, London, UK; \\ ${ }^{b}$ Danone Nutricia Research, Palaiseau, France
}

\begin{abstract}
Key Words
Drink $\cdot$ Installation $\cdot$ Social influence $\cdot$ Information . Experiment $\cdot$ Poland $\cdot$ Behavior change $\cdot$ Family $\cdot$ Home . Child $\cdot$ Nudge $\cdot$ Sweet beverage $\cdot$ Obesity $\cdot$ Prevention
\end{abstract}

\begin{abstract}
On average, children and adults in developed countries consume too little water, which can lead to negative health consequences. In a one-year longitudinal field experiment in Poland, we compared the impact of three home-based interventions on helping children and their parents/caregivers to develop sustainable increased plain water consumption habits. Fluid consumption of 334 children and their caregivers were recorded over one year using an online specific fluid dietary record. They were initially randomly allocated to one of the three following conditions: Control, Information (child and carer received information on the health benefits of water), or Placement (in addition to information, free small bottles of still water for a limited time period were delivered at home). After three months, half of the non-controls were randomly assigned to Community (child and caregiver engaged in an online community forum providing support on water consumption). All conditions significantly increased the water consumption of children (by 21.9-56.7\%) and of adults (by 22-89\%). Placement + Community generated the largest effects. Community enhanced the impact of Placement for children and parents, as well as the impact of Information for parents but not children. The
\end{abstract}

results suggest that the family setting offers considerable scope for successful installation of interventions encouraging children and caregivers to develop healthier consumption habits, in mutually reinforcing ways. Combining information, affordances, and social influence gives the best, and most sustainable, results.

(c) 2015 S. Karger AG, Basel

\section{Introduction}

Adequate water intake contributes to the overall health and well-being, enabling the body to maintain its mental and physical capabilities, and it helps in reducing energy intake and consequent risks of obesity [1]. However, in Europe, the water intake of children and adults remains below recommended levels [2]. There is, therefore, a public health issue of establishing healthy intake patterns in adult and children (whose habits may continue into adulthood).

This research assessed, over 12 months, the impact of home interventions on the water intake of children and parents. Home setting interventions are rare [3]; we identified only two such interventions on hydration habits [4, 5], and these focused on adolescents but did not involve parents. To the best of our knowledge, ours is the first research conducted on families at home, specifically designed to involve parents and to evaluate the impact on young children's fluid intake. 
Interventions targeting children's fluid intake frequently focus on the school environment $[1,6-8]$. However, there is evidence that home environment significantly influences eating patterns in young children [9]. Parents are crucial as role models [10] and as sources of imitation whose food preferences influence children's preferences [11]. Such effects are strongest for children aged 3-5 [12].

We aimed at identifying which of three interventions had the greatest impact on the water consumption of children. During the first intervention, as in traditional health belief studies [13], we provided information, relayed by parents, about the health benefits of water drinking. In the second, small 'kid size' bottles of water were delivered at the participants' home in order to increase the visibility and availability of water, after ideas of affordances from ecological psychology $[14,15]$ and echoing 'nudge' in behavioral psychology [16]. During the third, parents had access to an online discussion forum that provided norms of consumption and tips for change, after studies on the social influence of community for lasting behavioral changes [15, 17].

Installation Theory $[18,19]$ states that behavior is channelled by the combination of three layers of determinants: embodied knowledge, contextual affordances, and social influence. Therefore, we hypothesized that the greatest behavior change (e.g., the largest increase in water intake) would involve a combination of all three interventions, reflecting the three 'layers' of the 'installation' within the household.

\section{Methods}

Participants. 439 households in eight cities in Poland were involved. Eligible children were 3 to 6 years old, who drank a maximum $250 \mathrm{ml} /$ day of plain water of all kinds, consumed a minimum of $800 \mathrm{ml} /$ day of sweet hot or cold beverages, and failed to meet the EFSA adequate intake for total water intake of children.

\section{Study Design and Intervention}

The experimental design reflects the three layers of installation theory. Initially, participants were randomly allocated to one of three conditions (see figure 1): Control, receiving no intervention at all; Information, offered information and advice about water consumption; and Placement, offered information plus free water bottles at home. Three months later, half of the members of the Information and Placement groups were randomly allocated to the Community condition: an online community forum to exchange support. The study was conducted from May 2012 to May 2013.

Increasing Water Intake of Children and Parents in the Family Setting
The Research Ethics Committee of the Social Psychology Department at London School of Economics and the Bioethics Committee at the Institute of Food and Nutrition in Warsaw approved the protocol. Parents provided written informed consent.

Measures. The parents participating in this research completed a fluid-specific dietary record of the intake of all fluids for children and themselves, over 7 consecutive days [20], in each of six 'waves' (each intervention was assessed for short term effects immediately after; longer term effects were measured 3 weeks and 6 months after interventions - see fig. 1) the present analysis focuses on baseline (wave 1) and final results (wave 6). For in-depth analysis and methodological control, a subsample of five mothers recorded two full days of interaction with their child, using wearable miniature video-cameras, and participated in 'replay interviews' [21] of those recordings.

Data Analysis. We analyzed volumes of water intake, using analysis of variance carried out on SPSS (18.0) commercial software.

\section{Results}

At baseline, water consumption was well below the recommended adequate intake level [2] for children; the mean intake was below $55 \mathrm{ml} /$ day and that of parents was below $280 \mathrm{ml} /$ day.

Water intake significantly increased during and after the intervention, for parents and children in all conditions (table 1); all intervention groups significantly increased more than the control group. The largest increases in water intake were observed in the conditions with product placement (placement + community, $56.7 \%$ for children; and placement only, $88.6 \%$ for parents).

All conditions showed large effect sizes for children $\left(\eta^{2}\right.$ varied between 0.34 for the Control group and 0.54 for Placement + Community), whereas for parents the Placement Only $\left(\eta^{2}{ }_{p}=0.32\right)$ and Placement + Community $\left(\eta^{2}{ }_{p}=\right.$ $0.26)$ conditions showed large effect sizes. For children, Community increased intake for Placement (i.e., Placement + Community > Placement Only), but not for Information (i.e., Information + Community < Information Only). For parents, Community increased intake for Placement and (to a lesser degree) for Information. For children, Control increased the effect for approximately $50 \%$ of the interventions; for parents, the effect was $20 \%$ or less.

\section{Discussion}

These findings suggest that the habit of drinking water can be changed among both children and parents; indeed, combining the layers of installation led to the greater increase of daily water intake. The changes of water intake 


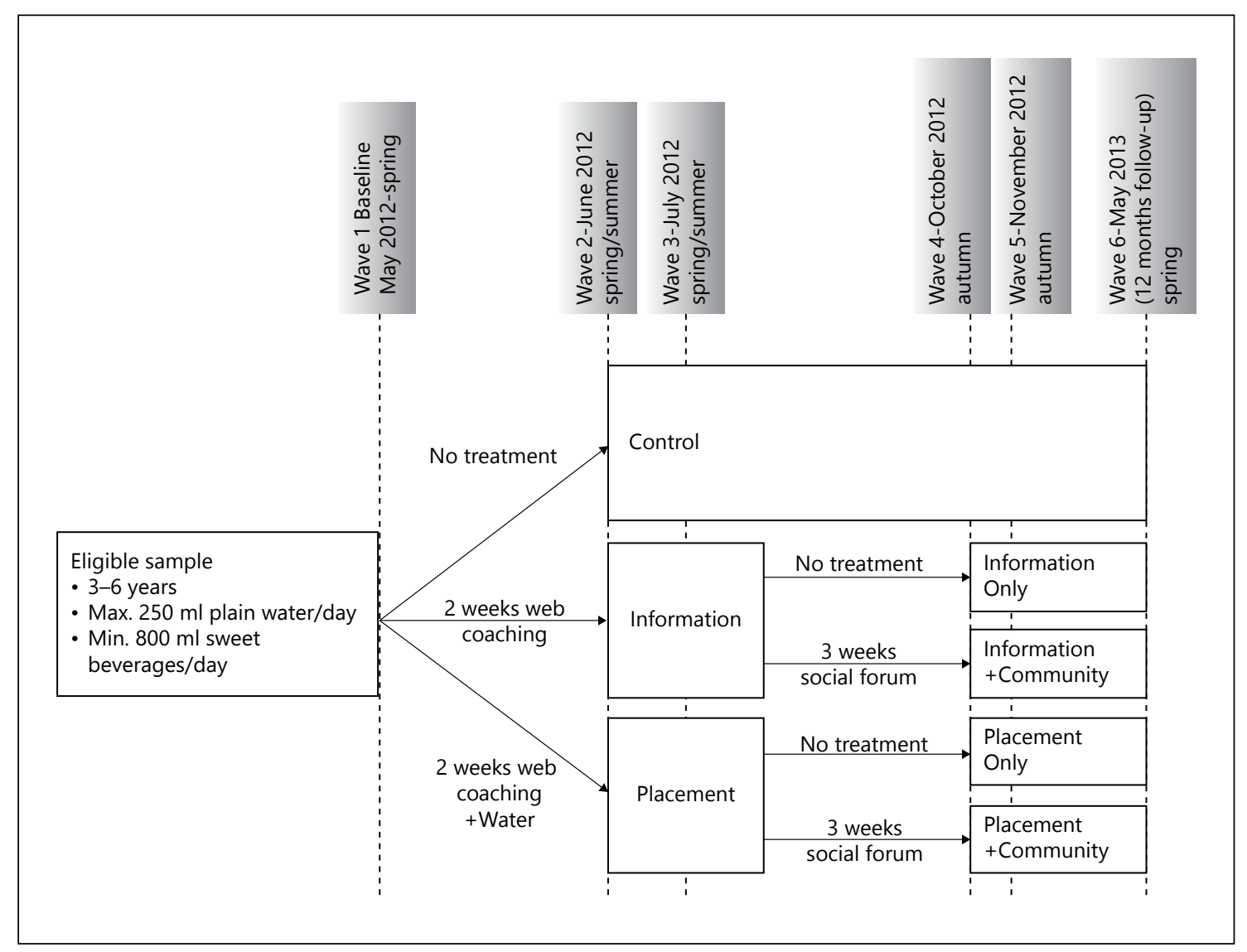

Fig. 1. Twelve-month study protocol.

Table 1. Evolution of total water intake for all groups at baseline (wave 1) and 12 months follow-up (wave 6)

\begin{tabular}{|c|c|c|c|c|c|c|c|c|c|c|}
\hline \multicolumn{6}{|l|}{ Children } & \multicolumn{5}{|l|}{ Parents } \\
\hline conditions & baseline & $\begin{array}{l}12 \\
\text { months }\end{array}$ & $\begin{array}{l}\text { mean } \\
\text { change } \\
(\mathrm{ml})\end{array}$ & $\begin{array}{l}\% \\
\text { change }\end{array}$ & $\begin{array}{l}\mathrm{p} \text {-value } \\
\text { and } \eta^{2}{ }^{*}\end{array}$ & baseline & $\begin{array}{l}12 \\
\text { months }\end{array}$ & $\begin{array}{l}\text { mean } \\
\text { change } \\
(\mathrm{ml})\end{array}$ & $\begin{array}{l}\% \\
\text { change }\end{array}$ & $\begin{array}{l}\mathrm{p} \text {-value } \\
\text { and } \eta_{\mathrm{p}}^{2}{ }^{*}\end{array}$ \\
\hline Control & $\begin{array}{l}53.7 \\
(83.4)\end{array}$ & $\begin{array}{l}171.4 \\
(156.5)\end{array}$ & 117.7 & 219.2 & $\begin{array}{l}0.00 \\
0.34\end{array}$ & $\begin{array}{l}277.2 \\
(277.4)\end{array}$ & $\begin{array}{l}338.6 \\
(244.3)\end{array}$ & 61.4 & 22.1 & $\begin{array}{l}0.02 \\
0.08\end{array}$ \\
\hline $\begin{array}{l}\text { Information } \\
\text { Only }\end{array}$ & $\begin{array}{l}44.0 \\
(67.3)\end{array}$ & $\begin{array}{l}265.9 \\
(315.0)\end{array}$ & 221.9 & 504.3 & $\begin{array}{l}0.00 \\
0.36\end{array}$ & $\begin{array}{l}262.8 \\
(315.1)\end{array}$ & $\begin{array}{l}477.4 \\
(518.8)\end{array}$ & 214.6 & 81.6 & $\begin{array}{l}0.00 \\
0.23\end{array}$ \\
\hline $\begin{array}{l}\text { Information + } \\
\text { Community }\end{array}$ & $\begin{array}{l}45.9 \\
(67.0)\end{array}$ & $\begin{array}{l}244.3 \\
(275.5)\end{array}$ & 198.4 & 432.2 & $\begin{array}{l}0.00 \\
0.34\end{array}$ & $\begin{array}{l}277.8 \\
(287.9)\end{array}$ & $\begin{array}{l}491.9 \\
(486.7)\end{array}$ & 214.1 & 77.1 & $\begin{array}{l}0.00 \\
0.18\end{array}$ \\
\hline $\begin{array}{l}\text { Placement } \\
\text { Only }\end{array}$ & $\begin{array}{l}39.6 \\
(57.4)\end{array}$ & $\begin{array}{l}197.5 \\
(195.8)\end{array}$ & 157.9 & 400 & $\begin{array}{l}0.00 \\
0.41\end{array}$ & $\begin{array}{l}181.1 \\
(229.3)\end{array}$ & $\begin{array}{l}341.5 \\
(293.5)\end{array}$ & 160.4 & 88.6 & $\begin{array}{l}0.00 \\
0.32\end{array}$ \\
\hline $\begin{array}{l}\text { Placement }+ \\
\text { Community }\end{array}$ & $\begin{array}{l}38.1 \\
(79.4)\end{array}$ & $\begin{array}{l}254.4 \\
(219.5)\end{array}$ & 216.3 & 567 & $\begin{array}{l}0.00 \\
0.54\end{array}$ & $\begin{array}{l}250.4 \\
(256.9)\end{array}$ & $\begin{array}{l}419.6 \\
(318.1)\end{array}$ & 169.2 & 67.5 & $\begin{array}{l}0.00 \\
0.26\end{array}$ \\
\hline
\end{tabular}

* Mean and standard deviation (in parentheses) of plain water intake (in $\mathrm{ml}$ ) and \% change. By convention, a partial eta-squared $\left(\eta^{2}\right.$ p $)$ value of 0 to 0.02 is a weak effect, 0.02 to 0.13 is a modest effect, 0.13 to 0.26 is a moderate effect, and $>0.26$ is a large (practically significant) effect. 
observed in the control group over the 12 months suggest that adults are less susceptible to social desirability and/or Hawthorne effects [22] than children. Parents intervened in the children's water consumption, varying by treatment and acting as gatekeepers of children's consumption. Analysis of video replay interviews illustrated this variation. Following Information recommendations, they offer children water, also drinking it themselves as role models. Following Placement, the visible presence of water bottles triggered water intake by children, by parents, and reminded parents to encourage children's drinking. The effect of Placement was even greater when the affordances (here small water bottles) were actually present (at month 3, 80.1\% increase for children and $11.8 \%$ increase for parents in Placement + Community); these effects decreased when the affordance was discontinued (water bottles were no longer made available to the household after month 3), before being stabilized at the final measure [20].

The impact of Placement on parents was also striking (i.e., resulting in the parents' only large effect size $\eta_{p}^{2}>0.26$ ); being a gatekeeper (i.e., organizing the choice of available drinks) for others influenced that person. The free water was placed in child-sized bottles for children's use, but taking concrete steps to make this choice available - directing the child's affordances for water drinking - increased both the child's consumption and the parents' own consumption. An important implication is that installation interventions develop feedback loops; specifically, nudging or influencing someone else's choices may also influence one's own choices. Both parent and child changes toward more healthy consumption were mutually reinforcing. This provides strong vindication for implementing healthy changes in family settings.

\section{Conclusion}

Increasing water consumption by children and parents is an important matter of public health policy, and our interventions show that this is possible. Informing parents and children about the health benefits of water can increase their water consumption. Combining this with the right affordances (e.g., an increased availability of water), the effect is greater and even more if combined with social influence (e.g., a community). Addressing the complete home 'installation' therefore appears a good ecological strategy for behavioral change.

\section{Acknowledgments}

The authors are grateful to Sky for diaries collection and contribution to data analysis; Liliana Naumik for participation in subcam data collection; and Bankole Falade for contribution to data analysis. This article benefited from a EURIAS fellowship at the Paris Institute for Advanced Studies (France), with the support of the European Union's 7th Framework Program for Research, and a funding from the French State managed by the Agence Nationale de la Recherche, program 'Investissements d'avenir,' (ANR-11LABX-0027-01 Labex RFIEA+).

\section{Disclosure Statement}

The authors have the following interests: This study was cofunded by Danone Research and LSE. SBM and IG are employees of Danone Research. SL and BF are employees of LSE. SL is an occasional consultant for Danone Research. Water bottles given to the subjects were products of a local subsidiary of Danone. No patents or products in development were linked to this study.

\section{References}

1 de Ruyter JC, Olthof MR, Seidell JC, Katan MB: A trial of sugar-free or sugar-sweetened beverages and body weight in children. $\mathrm{N}$ Engl J Med 2012, DOI: 10.1056/ NEJMoa1203034.

-2 EFSA Panel on Dietetic Products, Nutrition, and Allergies (NDA); Scientific Opinion on Dietary reference values for water. EFSA Journal 2010;8:1459. doi:10.2903/ j.efsa.2010.1459. Available online:www.efsa. europa.eu.

-3 Showell NN1, Fawole O, Segal J, Wilson RF, Cheskin LJ, Bleich SN, Wu Y, Lau B, Wang Y: A systematic review of home-based childhood obesity prevention studies. Pediatrics. 2013;132:e193-e200. doi: 10.1542/peds.20130786.

Increasing Water Intake of Children and Parents in the Family Setting
4 Ebbeling CB, Feldman HA, Osganian SK, Chomitz VR, Ellenbogen SJ, Ludwig DS: Effects of decreasing sugar-sweetened beverage consumption on body weight in adolescents: a randomized,controlled pilot study. Pediatrics 2006;117:673-680.

-5 Ebbeling CB, Feldman HA, Chomitz VR, Antonelli TA, Gortmaker SL, Osganian SK, Ludwig DS: A randomized trial of sugar-sweetened beverages and adolescent body weight. N Eng J Med 2012;367:1407-1406.

-6 James J, Thomas P, Cavan D, Kerr D: Preventing childhood obesity by reducing consumption of carbonated drinks: cluster randomized controlled trial. BMJ 2004;328:1237.

7 Muckelbauer R, Libuda L, Clausen K, et al. Promotion and provision of drinking water in schools for overweight prevention: randomized, controlledcluster trial. Pediatrics 2009; 123:e661-e667.

-8 Patel AI, Hampton KE: Encouraging consumption of water in school and child care settings: access, challenges, and strategies for improvement. Am J Public Health 2011;101: 1370-1379.

-9 Campbell KJ, Crawford DA, Ball K: Family food environment and dietary behaviors likely to promote fatness in 5-6 year-old children. Int J Obes (Lond) 2006;30:12721280.

10 Hart CN, Raynor HA, Jelalian E, Drotar D: The association of maternal food intake and infants' and toddlers' food intake. Child Care Health Dev 2010;36:396-403. 
11 Anzman SL, Rollins BY, Birch LL: Parental influence on children's early eating environments and obesity risk: Implications for prevention. Int J Obes 2010;34:1116-1124.

12 Papas MA, Hurley KM, Quigg AM, Oberlander SE, Black MM: Low-income, African American adolescent mothers and their toddlers exhibit similar dietary variety patterns. J Nutr Educ Behav 2009;41:87-94.

13 Becker MH, Radius SM, Rosenstock IM: Compliance with a medical regimen for asthma: a test of the health belief model. Public Health Rep 1978;93:268-277.

14 Barker RG: Ecological psychology: concepts and methods for studying the environment of human behavior. Stanford University Press, 1968.
15 Gibson JJ: The Ecological Approach to Visual Perception. London: Lawrence Erlbaum Associates, 1986.

16 Thaler RH, Sunstein CR: Nudge: Improving Decisions about Health, Wealth and Happiness. New Haven CT: Yale University Press, 2008.

17 Lewin KZ: Forces Behind Food Habits and Methods of Change. Bulletin of the National Research Council 1943;108:35-65.

18 Lahlou S: L'Installation du Monde. De la représentation à l'activité en situation. Habilitation thesis, Université de Provence, Aix-en-Provence, 2008.
9 Lahlou S: Social Representations and Social Construction: the Evolutionary Perspective of Installation Theory. In Sammut G, Andreouli E, Gaskell G, Valsiner J (eds), Handbook of Social Representations. Cambridge, UK: Cambridge University Press, 2015, 193-209.

20 Vergne S: Methodological Aspects of Fluid Intake Records and Surveys. Nutrition Today 2012;47:S57-S60.

21 Lahlou S, Le Bellu S, Boesen-Mariani S: Subjective Evidence Based Ethnography: Method and Applications. Integrative Psychological \& Behavioral Science. 2015, DOI: 10.1007/ s12124-014-9288-9.

22 Mayo E: Hawthorne and the Western Electric Company, The Social Problems of an Industrial Civilisation. London: Routledge and Keagan Paul, 1949. 